AperTO - Archivio Istituzionale Open Access dell'Università di Torino

\title{
Age specific reproductive success and cost in female Alpine ibex
}

\section{This is a pre print version of the following article:}

Original Citation:

Availability:

This version is available http://hdl.handle.net/2318/1507700

since 2016-10-06T16:42:31Z

Published version:

DOI:10.1007/s00442-014-3192-3

Terms of use:

Open Access

Anyone can freely access the full text of works made available as "Open Access". Works made available under a Creative Commons license can be used according to the terms and conditions of said license. Use of all other works requires consent of the right holder (author or publisher) if not exempted from copyright protection by the applicable law. 
Pre-print 6 December 2014

\section{Age-specific reproductive success and cost in female Alpine ibex}

MARCO RUGHETTI, Cerigefas - Wildlife Research Center. Fondazione dell'Università degli

Studi di Torino, Frazione Rore, 17 - 12020 Sampeyre (CN), Italy.

ANDREA DEMATTEIS, Cerigefas - Wildlife Research Center. Fondazione dell'Università degli

Studi di Torino, Frazione Rore, 17 - 12020 Sampeyre (CN), Italy.

PIER GIUSEPPE MENEGUZ, Cerigefas - Wildlife Research Center and, Dipartimento di Scienze

Veterinarie, Università degli Studi di Torino Largo Paolo Braccini 2 - 10095 Grugliasco (TO) Italy.

MARCO FESTA-BIANCHET, Département de biologie and Centre d'études nordiques, Université de Sherbrooke, Sherbrooke, Québec, J1K 2R1, Canada.

Corresponding author: Marco Rughetti. E-mail: marco_rughetti@libero.it

Author Contributions: AD and PGM conceived, designed and performed the experiments. MR and AD analyzed the data. MR and MFB wrote the manuscript. 


\begin{abstract}
In female mammals, reproduction requires high energy expenditure because of gestation and lactation, possibly leading to a fitness cost. Several studies, however, failed to find the expected negative correlation between current and future reproductive success, likely because of individual heterogeneity in reproductive potential. We compared reproductive performance and costs of reproduction for 40 female Alpine Ibex in one established population with 29 females translocated from the same population to a new colony. We investigate factors affecting pregnancy, fecundity and overwinter survival of juveniles, after accounting for individual heterogeneity. In both populations, prime-aged females experienced a strong reproductive cost. Senescent females, however, showed no evidence of reproductive costs. The colonizing population showed lower reproductive cost and better age-specific reproductive performance than the established population. We found a general pattern of low age-specific fecundity and reproductive success that was affected by environmental constraints. Age-specific reproductive success was unrelated to longevity. Although about $84 \%$ of adult females appeared to conceive, independently of environmental constraints, energy was allocated to reproduction in a highly conservative manner, leading to low age-specific fecundity (only 36 and $21 \%$ of prime-aged and senescent females were seen with a kid) but high kid survival (100\% to weaning and $92 \%$ to 1 year). Our results suggest that females embarked in lactation only if they had a very high probability of raising their offspring. Our study highlights how reproductive performance and costs in this species vary with age and environment, and are the result of a highly conservative reproductive tactic.
\end{abstract}

Key words: Alpine Ibex, environmental constraints, individual heterogeneity, permutation test, reproductive cost.

\title{
INTRODUCTION
}

Natural selection should favor individuals that allocate energy among maintenance, growth, survival and reproduction so as to maximize fitness (Fisher 1930, Stearns 1992, Williams 1966). Because reproduction is energetically expensive (Clutton-Brock et al. 1989, Gittleman and Thompson 1988) it may involve fitness costs, such as a decrease in survival (Descamps et al. 2006, Pistorius et al. 2008) or future reproduction (Beauplet et al. 2006, Clutton-Brock et al. 1996). The cost of reproduction is a central issue in evolutionary ecology (Fox et al. 2001, McNamara and Houston 1996, Roff 1992). Many studies on female mammals attempted to quantify fitness costs (Hamel et al. 2010b), that could arise from the high energy requirements of gestation and especially lactation (Gittleman and Thompson 1988). In large mammals, longevity is the main determinant of 
female reproductive success, because long-lived females have more breeding opportunities than short-lived ones (Clutton-Brock 1988, Weladji et al. 2006), therefore females adopt a conservative reproductive tactic. When environmental constraints are strong, they allocate available metabolic energy to survival rather than to reproduction (Festa-Bianchet et al. 1998, Martin and FestaBianchet 2010, Therrien et al. 2007). As a consequence, reproductive success is expected to decrease future reproduction rather than maternal survival. Survival costs of reproduction are rarely detected in large mammals and then only in juveniles, old females, or in years of very harsh environmental conditions (Clutton-Brock et al. 1983, Hamel et al. 2010b, Moyes et al. 2006, Tavecchia et al. 2005). Instead of the expected negative correlation between current and future reproductive success, however, several studies found no or positive correlations (review in Hamel et al. 2010b). Reproductive costs may be masked by individual heterogeneity in resource acquisition/allocation (Cam et al. 2002, Hamel et al. 2009, Wilson and Nussey 2009). Therefore, the covariation between current and future reproductive success depends on the magnitude of both reproductive cost and individual heterogeneity (Wilson and Nussey 2009). Individual heterogeneity may depend on age (Jones et al. 2008), early development (Lindström 1999) and environmental condition (Moyes et al. 2006), therefore several environmental and individual variables must be accounted for to assess reproductive costs (Hamel et al. 2010a). Reproductive costs are often more evident in light (Festa-Bianchet et al. 1998, Hamel et al. 2010a), primiparous (Green and Rothstein 1991, Langvatn et al. 2004), and old females (Clutton-Brock et al. 1983) at high density or in harsh environments (Bérubé et al. 1996). Age or environmental constraints may reduce the acquisition of resources to allocate to current and future reproduction, leading to a negative correlation.

We studied female reproductive performance in two populations of Alpine ibex (Capra Ibex), one long established, one recently reintroduced. We tested if current reproduction affects subsequent reproduction. Previous studies on this species revealed no reproductive cost in a colonizing population and a positive correlation of reproductive success in successive years in an established one (Toïgo et al. 2002). We first explored the effects of age and study area on reproductive success. We expected prime-aged females to have a better reproductive performance than young and senescent females, and predicted that reproductive success would be lower in the established than in the recently reintroduced population, because the latter should have had access to more abundant resources. We also sought to test if current reproduction was negatively affected by previous reproduction after accounting for age and study area. We used a permutation procedure to control for residual individual heterogeneity in reproductive potential. Finally, we tested if female reproductive status differed between long- and short-lived females. A negative correlation between longevity and current reproduction would suggest that short-lived females allocate energy to current 
reproduction to the detriment of survival. Because large herbivore females usually adopt a conservative reproductive tactic (Festa-Bianchet and Jorgenson 1998, Martin and Festa-Bianchet 2010) we did not expect to find an effect of current reproduction on longevity.

\section{MATERIALS AND METHODS}

\section{Study areas}

The Alpi Marittime Natural Park is in southwestern Piedmont, Italy, on the border with France. The ibex population in this protected area results from reintroductions in 1920 to 1932 of 22 animals from the Gran Paradiso National Park (Floriani 1975). The population was estimated at about 250 in 1962 (Coutourier 1962). In 1972, the estimated population size in the core area of the original reintroduction reached 537 animals, decreased to 237 in 1980 and increased again until 2003 when it was estimated at about 500 (Dematteis 2005). Between 1986 and 2004, about 300 ibex were captured and reintroduced both elsewhere in the Italian Alps and inside the park. The Alpi Cozie study area is in the southwestern Alps of Piedmont, just north of the Alpi Marittime. The ibex population in this area results from natural immigration and transplants from Alpi Marittime, and increased from 65 in 2001 to 116 in 2004.

\section{Population data}

We analyzed data on 158 females aged two years and older captured in the park by dart gun, mostly in May, and released either inside the park or elsewhere in the Alps from 1986 to 2006. Female age was precisely determined by counting horn annuli (Ratti and Habermehl 1977), and gestation status was determined by abdominal palpation. Body mass was recorded for 142 females. Reliability of abdominal palpation was tested with ecographies for 63 females. Palpation never recorded a false pregnancy and failed to detect a pregnancy for 4 of 43 pregnant females (Dematteis 2005). We individually marked and monitored 69 females. Of these, 30 were captured in $1986-1989$ and released in the park close to the core area of the original reintroduction. Of 39 females captured in 1999 - 2006, 10 were released inside the park and 29 about $50 \mathrm{~km}$ to the north in the Alpi Cozie. All females were intensively monitored inside the park from 1986 to 1996 by park wardens, and from 1998 to 2006 by technicians of the University of Turin involved in the Alpi Cozie reintroduction project. In our study areas females give birth in late May and in June. Kids were not marked, therefore female fecundity, reproductive success, and kid overwinter survival were respectively monitored by the presence of a kid at heel in late May and June, in autumn, and early the following April, before females gave birth again. Each female was observed at least three times within the month of June, and the presence of a kid was noted. In autumn and early April kid 
survival was assessed when two consecutive observations confirmed female-kid bond. Animals were captured and handled following procedures established by the Italian Ministry of the Environment.

\section{Statistical analysis}

We used data on all females captured in the park to explore age-specific pregnancy rate. We fitted a general linear model with a binomial distribution and logit-link function to estimate the probability that a female was pregnant. Age was set as explanatory variable. We compared three models: age as factor, two age classes ( 3 years, 4 years and older) and three age classes. For the last model age classes were defined following Toïgo et al. (2002): 3 years; 4 - 9 years (prime-aged); 10 years and older (senescent).

We also examined how female mass varied with age. We fitted a linear regression of body mass as a function of age. Age was set as a categorical variable with 10 levels (2 to 11 years and older). To asses when females stop growing, we fitted 8 models where the minimum age included was progressively advanced: first from age 3 to 11, then from age 4 to 11, and so on. After identifying at what age females stop growing, we tested for a decrease in mass in older ages. Using only fully grown females, we used the same approach progressively reducing the maximum age included.

We used data from long-term monitoring to explore age-specific reproductive performance of individual females. We fitted a generalised linear mixed model with current reproductive success (definite as the presence of a kid in autumn) as a binomial response with logit-link function and age and study area as explanatory variables. Following Toïgo et al. (2002), age was set as a 3-level variable: 3 years; 4 - 9 years (prime-aged); 10 years and older (senescent). Two-year-olds were not considered because of the small sample size (3 individuals). Female identity and year were set as random effects with varying intercepts and fixed slopes. We refer to the selected model of this analysis as base model. To assess the presence of a reproductive cost, we added reproductive success the previous year as a binomial explanatory variable to the base model and tested its main effect and higher order interactions. We estimated repeatability (between-individual variance over total variance) in probability of current reproduction for female ibex following Nakagawa and Schielzeth (2010).

To test if reproductive costs differed between study areas, we compared the study areaspecific costs separately for adult and senescent females using estimates from the selected model from the previous analysis on reproductive cost. We defined reproductive cost as $1-\mathrm{RS}_{\mathrm{R}} / \mathrm{RS}_{\mathrm{N}}$ (Tavecchia et al. 2005), where $\mathrm{RS}_{\mathrm{R}}$ and $\mathrm{RS}_{\mathrm{N}}$ are the estimated reproductive successes in year $t$ 
respectively of females reproducing and not reproducing in year $t$ - 1 . The Wald chi-square test statistic with 1 degree of freedom was calculated as: $(b 1-b 2)^{2} /\left(S E 1^{2}+S E 2^{2}\right)$, where $b 1$ and $b 2$ are the estimated study area-specific reproductive costs, and SE1 and SE2 their standard errors. We used the $\delta$-method to estimate standard error.

To test if costs of reproduction were masked by individual heterogeneity, we performed a permutation test following Morin (2013), to determine if the sequence of yearly successes and failures of each female differs from random. We first fitted separately for adult and senescent females the model on reproductive cost selected by the previous analysis. We then ran each model 10000 times permuting the intra-individual pattern of successes and failures. For each female the number of successes and failures remained the same but the order was changed. Finally, for each age class we compared the distribution of the estimated slopes of the effect of previous reproduction on current reproduction obtained from simulations with the slope obtained from observed data. If the observed slope was within the $2.5 \%$ extremes of the distribution of the permutated estimated slopes, it was considered significant. If it was in the lower extreme, then females alternated successes and failures more often than expected if there were no costs of reproduction, leading to a negative correlation. The opposite was true, if the observed slope was within the upper extreme of the distribution.

To test for a prolonged effect of current reproductive success on future probability of reproduction, we considered only females with at least three consecutive years of reproductive data. We added as explanatory variable to the base model a categorical variable with three levels indicating the number of years when a female skipped reproduction: females that reproduced the previous year (0 year skipped), females that did not reproduce the previous year but reproduced two years before ( 1 year skipped) and females that did not reproduce in either of the two previous years ( 2 years skipped). If females that skipped more than one year had a reproductive success higher than female that skipped only one year, the hypothesis of a prolonged effect of current reproduction would be supported. We compared the model with three levels of the categorical variable, with the model with only two levels (females that did and did not reproduce the previous year).

To test for longevity effects on age-specific reproductive success, we considered 30 females captured in 1986-1987 and monitored in the park until death. We fitted a generalised linear mixed model with yearly reproductive success as binomial response with logit-link function, and age class (3 years old, adult and senescent) and longevity as explanatory variables. Female identity was set as random effect with varying intercept and fixed slope. We compared three models: main effects and interaction, main effects only, and just the effect of age. Longevity was defined as the age at last observation. The probability that a female was missed for two consecutive years was lower than 
0.0064. The lower bound of Bayesian 95\% credible interval for the resighting probability was 0.92 . This estimate was calculated as the $2.5^{\text {th }}$ percentile of 100,000 samples drawn by Markov Chain Monte Carlo from a binomial posterior distribution assuming an uninformative prior and setting identity as random effect.

All analyses were conducted in R (R Development Core Team 2013). Mixed model were fitted with the lme4 package. Following Pinheiro and Bates (2000), we selected the random component of the model by restricted maximum likelihood. To select the fixed component we compared a set of candidate models fitted with maximum likelihood estimation using the Akaike Information Criterion corrected for finite sample size (AICc; Burnham and Anderson 2002). When the difference between two models was $<2$ AICc units, we selected the model with fewer degrees of freedom (Burnham and Anderson 2002). We used the selected model fitted with restricted maximum likelihood to make inferences.

\section{RESULTS}

Primiparity in the park was at three and four years. None of 13 two-year-old females were pregnant and $40 \%(n=26$; C.I. $95 \%=23-60 \%)$ of females were pregnant at age three. Pregnancy rate for females aged 4 years and older averaged $84 \%(n=149$; C.I. $95 \%=76-90 \%)$, and did not differ between prime-aged and senescent females. A model with three age classes ( 3 years, prime-aged and senescent $)$ did not perform better $(\triangle \mathrm{AICc}=2.056)$ than a model with two classes $(3$ years, 4 years and older).

Age explained $60 \%$ of the variability in body mass. Body mass increased from 2 to 7 years, and age classes from 7 to 11 did not differ in mass (Figure 1). A model with age as categorical variable with 10 levels (ages 2 to 11) had a poorer fit to the data than a model with 5 age classes $(\triangle \mathrm{AICc}=4.59$. Estimate and $\mathrm{SE}$ for selected model: intercept, 22.61, 1.316; age class (3), 8.35, 1.649; age class (4), 11.73, 1.793; age class (5), 13.80, 1.719; age class (6), 13.83, 1.719; age class (7-11), 18.26, 1.439). Further models that sought to detect a decrease in mass in older ages had higher AICc values. All 98 kids (56 in the park and 51 in the Alpi Cozie) observed in May and June between 1986 and 2005 survived to late autumn, and only 9 died during winter (92\% survival; I.C. $95 \%=80-97 \%)$.

There were large differences in reproductive success between study sites, and to a lesser extent among age classes (Figure2). There was no statistical difference between 3 year-old and senescent females, whereas prime-aged females had higher reproductive success. The pattern was similar for both study sites, but in the park females had a lower age-specific reproductive success than in Alpi Cozie (Estimate and SE for selected model in table 1: intercept, -1.09, 0.801; age class 
(adult), 1.66, 0.817; age class (senescent), 0.87, 0.834; study area (park), -1.12, 0.263). The interaction between population and age class did not improve the model (Table 1). Year as random factor was not statistically significant $\left(\chi^{2}=1.885 ; \mathrm{P}=0.17\right)$ and was not considered in further analysis. Female identity was not statistically significant (Between individual variance $=2.46^{*} 10^{-13}$. LRT: $\chi^{2}=-7.88^{*} 10^{-8} ; \mathrm{P} \sim 1$ ), but we retained it in the model because we were interested in individual heterogeneity.

For prime-aged females, successful reproduction the previous year substantially reduced the probability of current reproduction (Figure 3), but the trend appeared reversed for senescent females, for which the effect was not statistically significant (Estimate and SE for selected model in table 2: intercept, 1.60, 0.390; age class (senescent), -1.97, 0.451; previous reproduction, -1.24, 0.412 ; study area (park), $-1.50,0.344$; age class * previous reproduction, 1.82, 0.647). The interaction between previous reproduction and study area did not improve the model (Table 2). Female identity was not statistically significant (Between individual variance $=0$. LRT: $\chi^{2}=-$ $4.99 * 10^{-8} ; \mathrm{P} \sim 1$ ). Repeatability in female probability of reproduction was $0.001(\mathrm{SE}=0.075)$. For prime-aged females the reproductive cost estimated from the model in table 2 was greater in the $\operatorname{park}(0.54 ; \mathrm{SE}=0.062)$ than in the Alpi Cozie $\left(0.29 ; \mathrm{SE}=0.089\right.$. Wald test, $\chi^{2}, 1 \mathrm{df}=5.144, \mathrm{P}=$ $0.023)$.

Permutation tests largely confirmed the results of previous analyses. For prime-aged females the observed effect of previous reproduction on current reproduction was much lower than that expected from randomness (Table 3). On the contrary for senescent females the observed estimate was greater than that expected from the distribution of simulated values but the difference was not statistically significant (Table 3).

Females aged four years and older weaned kids in two consecutive years in 37 occasions, whereas in 34 and 15 occasions, females skipped one or more consecutive reproductive opportunities. After accounting for age, there was no difference in yearly probability of reproduction among females that skipped one or more reproductive opportunities (AICc increased by 3.76). Female identity was not statistically significant (Between individual variance $=0$. LRT: $\chi^{2}$ $\left.=-6.46^{*} 10^{-8} ; \mathrm{P} \sim 1\right)$.

Age at death average 13 years and ranged from 6 to 19. None of 30 females monitored until death reproduced in the last two years of life. We detected no effects of longevity on yearly probability of reproduction. Age was the only detectable response variable, and longevity did not improve the model (AICc increased by 2.02). Female identity was not statistically significant (Between individual variance $=0$. LRT: $\chi^{2}=-3.79 * 10^{-8} ; \mathrm{P} \sim 1$ ). 


\section{DISCUSSION}

Our two most important results are that prime-aged females experienced a high reproductive cost that disappeared in older ages, and that females from the same original population had a much greater reproductive output after release into new habitat. We also found low age-specific reproductive success despite high pregnancy rates, and very high kid survival compared to most other studies of ungulates (Gaillard et al. 2000). Finally, we found no effects of longevity on agespecific reproductive success. These findings agree with previous results for this species (Toïgo et al. 2007, Toïgo et al. 2002), and confirm that female ibex adopt a very conservative reproductive tactic, possibly more so than other capital breeding ungulates. Our results suggest that females embarked in lactation only if they had a very high probability of raising their offspring to 1 year of age.

In the Park, primiparity was at three and mostly at four years. Although $40 \%$ of three-yearold females were pregnant, only $10 \%$ were seen with a kid at heel in June. Reproductive success of reintroduced 3-year-old females in the Alpi Cozie seemed higher than in the park at 25\%, suggesting a positive effects of low density. Age of primiparity in the colonizing population, however, was likely delayed by the fact that all 2 and 3-year-old females monitored were captured in the park and therefore experienced during early development the same environmental constraints as females in the Park. Reproductive success of senescent females was lower than for prime-aged females in both populations. Reproductive performance in the colonizing population was much higher than in the park, suggesting that females in the latter were strongly affected by environmental constraints.

Age and environmental constraints commonly affect reproduction in large herbivores (Bonenfant et al. 2009, Gaillard et al. 2000). Ibex in the colonizing population of Belledonne and in the stable population of Vanoise (Toïgo et al. 2002) were sometimes primiparous at two years. In Belledonne the reproductive rate of three-year-old and prime-aged females was nearly $80 \%$, whereas in Vanoise prime-aged reproductive rate was $45 \%$. These values suggest that our study populations experienced strong environmental constraints, that decrease the reproductive rate of both primiparous and prime-aged females (Figure 2).

In our study areas, prime-aged female ibex experienced strong reproductive costs, but senescent females did not. The absence of reproductive cost in senescent females may be due to a more conservative reproductive tactic compared to prime-aged females, so that only females in very good condition reproduced, leading to a low reproductive rate in this age class. The large reproductive cost shown by prime-aged females may be partly due to continued growth. A similar pattern was observed in mountain goats (Oreamnos americanus), where reproductive cost decreased 
with age (Hamel et al. 2010a). In goats, older females had high social rank and may have acquired more experience in raising offspring (Hamel et al. 2010a, Côté and Festa-Bianchet 2001). Female ibex have a slow growth pattern, similarly to mountain goats (Festa-Bianchet and Côté 2008), and reach maximum mass at about 7 years of age, whereas reproductive cost disappeared at 9 years. The absence of reproductive cost in senescent females may also be due to higher survival to older ages of females with higher reproductive potential, possibly because of greater skills in resource acquisition. However, this hypothesis is unlikely for two main reasons. First, female survival is generally very high in this species (Toïgo et al. 2007). Second, longevity was not correlated with yearly probability of reproduction, and no female died the year after weaning a kid. These results suggest no effect of reproduction on survival, in agreement with results for other ungulates (Hamel et al. 2010b). They also imply that the age-specific reproductive tactic of female ibex is the opposite of that predicted by the terminal investment hypothesis (Clutton-Brock 1984): older females reduce reproductive effort rather than increase it. Alternatively, the low reproductive rate in senescent females may partially explain the absence of a reproductive cost. This hypothesis cannot be totally excluded but is not supported by our results. Indeed the consequence of current reproduction for subsequent reproduction in senescent females was clearly opposite to that observed in prime-aged females, in both populations (Figure 3). In addition, although reproductive rate was higher in senescent females of the colonizing population than in prime-aged females in the stable one (Figure 2), a reproductive cost was detected only in the latter.

Toïgo et al. (2002) recognized that the positive correlation between current and successive reproduction in the ibex population of Vanoise may be due to unmeasured individual heterogeneity. Individual heterogeneity depends on multiple phenotypic traits (Wilson and Nussey 2009), and studies that control for individual traits are more likely to provide evidence of a reproductive cost (Hamel et al. 2010b). Measurements of multiple traits, however, are rarely available, and even when they are, an unmeasured trait may affect the results (Wilson and Nussey 2009). Our analysis accounted for individual heterogeneity statistically by permutation, comparing observed reproductive success in successive years over a female's lifetime with that expected assuming a random sequence of successful and unsuccessful reproductive events. In our study, prime-aged females reproduced in two consecutive years less frequently than expected, likely because of a strong reproductive cost, combined with a conservative reproductive tactic. Senescent females, however, alternated between successes and failures as expected if there were no costs of reproduction. The absence of reproductive cost in senescent females suggests an increasingly conservative reproductive tactic with age, so that females reproduced only when in very good condition. 
The selected model on reproductive cost reveals a low between-individual variance in reproductive schedules, and the permutation test confirmed these results. Apparently, we were able to detect a clear cost of reproduction in prime-aged females because of a combination of low individual variability in reproductive schedules, strong environmental constraints and a strong fitness cost of reproduction. On the contrary in the Vanoise and Belledonne populations (Toïgo et al. 2002), weaker environmental constraints, and large between-individual variance in resource acquisition/allocation may explain the failure to detect a reproductive cost.

This reintroduction projected offered a unique opportunity to test for differences in reproductive performance and costs for the same population when exposed to different environments. For prime-aged females in the park, previous reproduction decreased the probability of current reproductive success by $54 \%$, compared to $29 \%$ in the Alpi Cozie. That difference was expected because the newly introduced population had more access to food resources, which may decrease heterogeneity in resource acquisition/allocation among individuals (van Noordwijk and de Jong 1986), and lower the cost of reproduction. The age-specific reproductive rate in Alpi Cozie, although higher than the park, was lower than reported for other increasing ibex populations (Loison et al. 2002, Toïgo et al. 2002), possibly because of environmental constraints experienced by translocated females during early development in the park (Festa-Bianchet et al. 2000, Lindström 1999). Early life conditions may decrease female reproductive potential more than current environmental constraints and make reproductive cost easier to detect.

Female ibex have a very high survival rate (Toïgo et al. 2007) but fecundity is much lower than for other ungulates of similar or larger mass. Gaillard et al. (2000) reported for 51 populations of wild ungulates an average fecundity of prime-aged females of 0.82 . This value is similar to that found in increasing ibex populations (Loison et al. 2002, Toïgo et al. 2002). Stable populations show a prime-aged fecundity of 0.36 (this study) or 0.45 (Toïgo et al. 2002). Our study is the first to measure ibex pregnancy rate in a wild population and suggests that pregnancy has a low cost for adult females. Age-specific pregnancy rate was available only for animals captured in the park. About $84 \%$ of females aged 4 years and older were pregnant, although delayed primiparity and agespecific reproductive success suggested strong environmental constraints. In June, within $2-4$ weeks of being captured, only 36 and $21 \%$ of prime-aged and senescent females had a kid at heel. Therefore, perinatal kid mortality must have been about 57 and $75 \%$ for prime-aged and senescent females respectively. Once a kid was observed with his mother, kid mortality was not recorded until winter, and more than $90 \%$ of kids survived to yearling age. High kid survival was reported for this species by other studies (Largo et al. 2008, Toïgo et al. 2002) and suggests a general pattern of high survival also in early life. 
Despite the apparently low genetic variability of the ibex population in the Maritime Alps (Maudet et al. 2002), we found juvenile survival rate similar to those observed in other populations (Largo et al. 2008, Toïgo et al. 2002).

Because ecographies took place in late pregnancy, and foetus were alive, we can exclude embryo resorption, and suspect instead high perinatal mortality to explain the large difference between pregnancy rate and observed kids at heel. Limited energy allocated from females to foetus in the last weeks of pregnancy may lead to a poor intrauterine growth. Neonates in poor condition or sick at birth may die shortly after or may be abandoned by their mothers.

Most adult females apparently conceived independently of environmental constraints, whereas postnatal energy allocation to reproduction was highly conservative, leading to a life history strategy of high adult survival, low female fecundity, and high kid survival. In mammals, fitness component sensitive to reproductive costs depend on life speed, with slow-living species allocating resources to adult survival rather than reproduction (Hamel et al. 2010b). The reproductive cost in female ibex is paid by neonatal kids. A combination of postpartum female body condition and environmental conditions in spring may determine perinatal survival. Females with insufficient reserves may allocate energy to their own survival rather than to a reproduction whose result is uncertain.

\section{ACKNOWLEDGEMENT}

Funding was provided by the Alpi Marittime Natural Park and the Province of Cuneo, Italy. We thank the Alpi Marittime Natural Park for their long-term effort in research and management of mountain ungulates. Particular thanks are due to the park wardens for capturing and monitoring animals. We thank Livio Martino, Fabrizio Rostagno, Arianna Menzano and Paolo Tizzani for help in fieldwork. Thanks to Fanie Pelletier for preliminary data analysis and to Audrée Morin for developing the permutation test. We also thank Jean-Michel Gaillard, Carole Toïgo, and an anonymous reviver for insightful comments on previous draft of this paper. 


\section{REFERENCES}

Beauplet G, Barbraud C, Dabin W, Küssener C, Guinet C (2006) Age-specific survival and reproductive performances in fur seals: evidence of senescence and individual quality. Oikos 112:430-441

Bérubé CH, Festa-Bianchet M, Jorgenson JT (1996) Reproductive costs of sons and daughters in Rocky Mountain bighorn sheep. Behav Ecol 7:60-68

Bonenfant C et al. (2009) Empirical evidence of density-dependence in populations of large herbivores. Adv Ecol Res 41:313-357

Burnham KP, Anderson DR (2002) Model selection and multimodel inference: a practical information - theoretic approach, 2dn. Springer Verlag, New York

Cam E, Link WA, Cooch EG, Monnat JY, Danchin E (2002) Individual covariation in life-history traits: seeing the trees despite the forest. Am Nat 159:96-105

Clutton-Brock TH (1988) Reproductive success: studies of individual variation in contrasting breeding systems. University of Chicago Press, Chicago, London

Clutton-Brock TH (1984) Reproductive effort and terminal investment in iteroparous animals. Am Nat 123: $212-229$

Clutton-Brock TH, Albon SD, Guinness FE (1989) Fitness costs of gestation and lactation in wild mammals. Nature 337:260-262

Clutton-Brock TH, Guinness FE, Albon SD (1983) The costs of reproduction to red deer hinds. J Anim Ecol 52:367383

Clutton-Brock TH, Stevenson IR, Marrow P, MacColl AD, Houston AI, McNamara JM (1996) Population fluctuations, reproductive costs and life-history tactics in female Soay sheep. J Anim Ecol 65:675-689

Côté SD, Festa-Bianchet M (2000) Dominance hierarchies in female mountain goats: stability, aggressiveness and determinants of rank. Behaviour 137:1541-1566

Couturier M (1962) Le Bouquetin des Alpes, Grenoble

Dematteis A (2005) Ecologia riproduttiva delle femmine di stambecco nella popolazione delle Alpi Marittime. Scienze Veterinarie. Università degli studi di Torino, Torino, pp 213

Descamps S, Boutin S, Berteaux D, Gaillard JM (2006) Best squirrels trade a long life for an early reproduction. Proc R Soc B 273:2369-2374

Festa-Bianchet M, Côté SD (2008) Body and Horn growth. In: Mountain Goats. Island Press, Washington, pp 91-117

Festa-Bianchet M, Jorgenson JT, Réale D (2000) Early development, adult mass, and reproductive success in bighorn sheep. Behav Ecol 11:633-639

Festa-Bianchet M, Gaillard J-M, Jorgenson JT (1998) Mass- and density-dependent reproductive success and reproductive costs in a capital breeder. Am. Nat. 152:367-379

Festa-Bianchet M, Jorgenson JT (1998) Selfish mothers: reproductive expenditure and resource availability in bighorn ewes. Behav Ecol 9:144-150

Fisher RA (1930) The genetical theory of natural selection. Clarendon Press, Oxford.

Floriani D (1975) Stambecco. Sui sentieri del RE. Cuneo, pp 98-104

Fox CW, Roff DA, Fairbairn DJ (2001) Evolutionary ecology. Concepts and case studies. Oxford university press, Oxford

Gaillard J-M, Festa-Bianchet M, Yoccoz NG, Loison A, Toïgo C (2000a) Temporal variation in fitness components and population dynamics of large herbivores. Annu Rev Ecol Syst 31:367-393

Gittleman JL, Thompson SD (1988) Energy allocation in mammalian reproduction. Amer Zool 3:863-875

Green WCH, Rothstein A (1991) Trade-offs between growth and reproduction in female bison. Oecologia 86:521-527

Hamel S, Côté SD, Festa-Bianchet. M (2010a) Maternal characteristics and environment affect the costs of reproduction in female mountain goat. Ecology 91:2034-2043

Hamel S, Jean-Michel Gaillard, Yoccoz NG, Anne Loison, Bonenfant C, Descamps S (2010b) Fitness costs of reproduction depend on life speed: empirical evidence from mammalian populations. Ecol Lett 13: 915-935

Hamel S, Côté SD, Gaillard J-M, Festa-Bianchet M (2009) Individual variation in reproductive costs of reproduction: high-quality females always do better. J Anim Ecol 78:143-151

Jones OR et al. (2008) Senescence rates are determined by ranking on the fast-slow life-history continuum. Ecol Lett 11:664-673

Langvatn R, Mysterud A, Stenseth NC, Yoccoz NG (2004) Timing and synchrony of ovulation in red deer constrained by short northern summers. Am Nat 163:763-772

Largo E et al. (2008) Can ground counts reliably monitor ibex Capra ibex populations? Wildlife Biol 14:489-499

Lindström J (1999) Early development and fitness in birds and mammals. Trends Ecol Evol 14:343-348

Loison A, Toïgo C, Appolinaire J, Michallet J (2002) Demographic processes in colonizing populations of isard (Rupicapra pyrenaica) and ibex (Capra ibex). J Zool 256:199-205

Martin JG, Festa-Bianchet M (2010) Bighorn ewes transfer the costs of reproduction to their lambs. Am Nat 176:414423

Maudet C et al. (2002) Microsatellite DNA and recent statistical methods in wildlife conservation management: applications in Alpine ibex [Capra ibex (ibex)]. Mol Ecol 11: 421-436 
McNamara JM, Houston AI (1996) State-dependent life histories. Nature 380:215-221

Morin A (2013) Age-dependent costs of reproduction in female Alpine chamois (Rupicapra rupicapra). Master thesis. Université de Sherbrooke, Sherbrooke, pp $22-66$

Moyes K, Coulson T, Morgan BJT, Donald A, Morris SJ, Clutton-Brock TH (2006) Cumulative reproduction and survival costs in female red deer. Oikos 115:241-252

Nakagawa S, Schielzeth H (2010) Repeatability for Gaussian and non-Gaussian data: A practical guide for biologists. Biol Rev 85:935-956

Pinheiro JC, Bates DM (2000) Mixed-effects models in S and S-PLUS. Springer-Verlag, New York

Pistorius PA, Bester MN, Hofmeyr GJG, Stephen P. Kirkman, Taylor FE (2008) Seasonal survival and the relative cost of first reproduction in adult female southern elephant seals. J Mammal 89:567-574

Ratti P, Habermehl KH (1977) Untersuchen zur Altersschätzung und Alterbestimmung beim Alpensteinbock (Capra ibex ibex) im Kanton Graubunden. Z. Jagdwiss 4:188-213

R Development Core Team. 2013. R: A language and environment for statistical computing. R Foundation for Statistical Computing, Vienna, Austria. ISBN 3-900051-07-0, URL http://www.R-project.org.

Roff DA (1992) The evolution of life histories. Chapman and Hall, New York

Stearns SC (1992) The evolution of life histories. Oxford University Press, Oxford

Tavecchia G et al. (2005) Predictors of reproductive cost in female Soay sheep. J Anim Ecol 74:201-213

Therrien J-F, Côté SD, Festa-Bianchet M, Ouellet J-P (2007) Conservative maternal care in an iteroparous mammal: a resource allocation experiment. Behav Ecol Sociobiol 62:193-199

Toïgo C, Gaillard J-M, Festa-Bianchet M, Largo É, Michallet J, Maillard D (2007) Sex- and age-specific survival of the highly dimorphic Alpine ibex: evidence for a conservative life-history tactic. J Anim Ecol 76:679-686

Toïgo C, Gaillard J-M, Gauthier D, Girard I, Martinot JP, Michallet J (2002) Female reproductive success and costs in an alpine capital breeder under contrasting environments. Ecoscience 9:427-433

van Noordwijk AJ and de Jong G (1986) Acquisition and allocation of resources: their influence on variation in life history tactics. Am Nat 128: 137-142.

Weladji RB et al. (2006) Good reindeer mothers live longer and become better in raising offspring. Proc. R. Soc. B 273:1239-1244

Williams GC (1966) Natural selection, the cost of reproduction, and a refinement of Lack's principle. Am Nat 100:67690

Wilson AJ, Nussey DH (2009) What is individual quality? An evolutionary perspective. Trends Ecol Evol 25:207-214 


\section{FIGURES AND TABLES}

Fig. 1 Age-specific body mass of 142 female ibex aged 2 years and older captured in May in the Alpi Marittime Natural Park, southern Piedmont, Italy, from 1986 to 2006. Age 11 includes females aged 11 years and older.

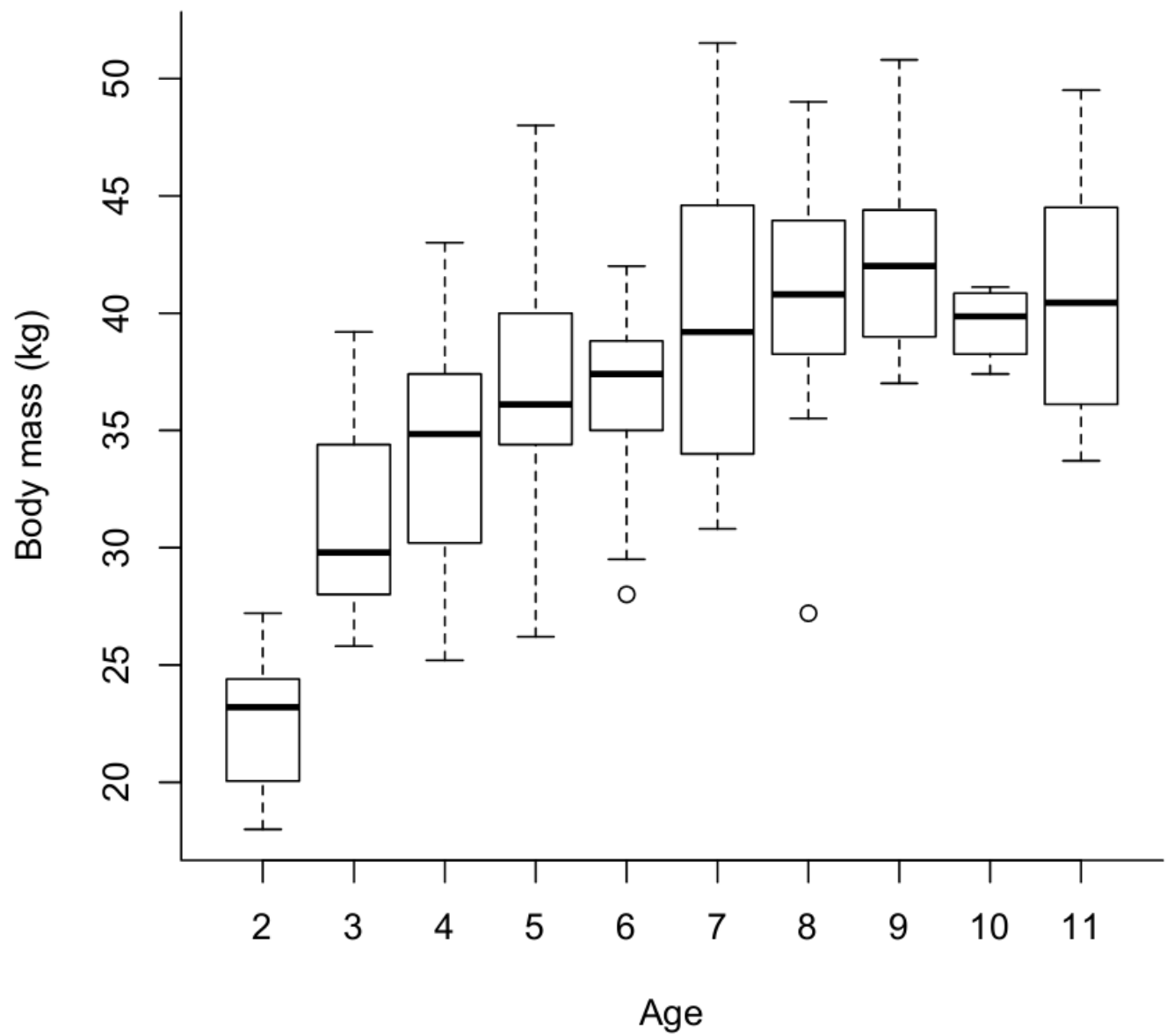


Fig. 2 Effects of age on reproductive success (production of a kid that survived until autumn) of a) 40 female ibex (217 female-years) monitored in Alpi Marittime Natural Park from 1986 to 2006 and b) 29 female ibex (109 female-years) monitored in the Alpi Cozie from 1999 to 2006, based on the selected model in table 1.
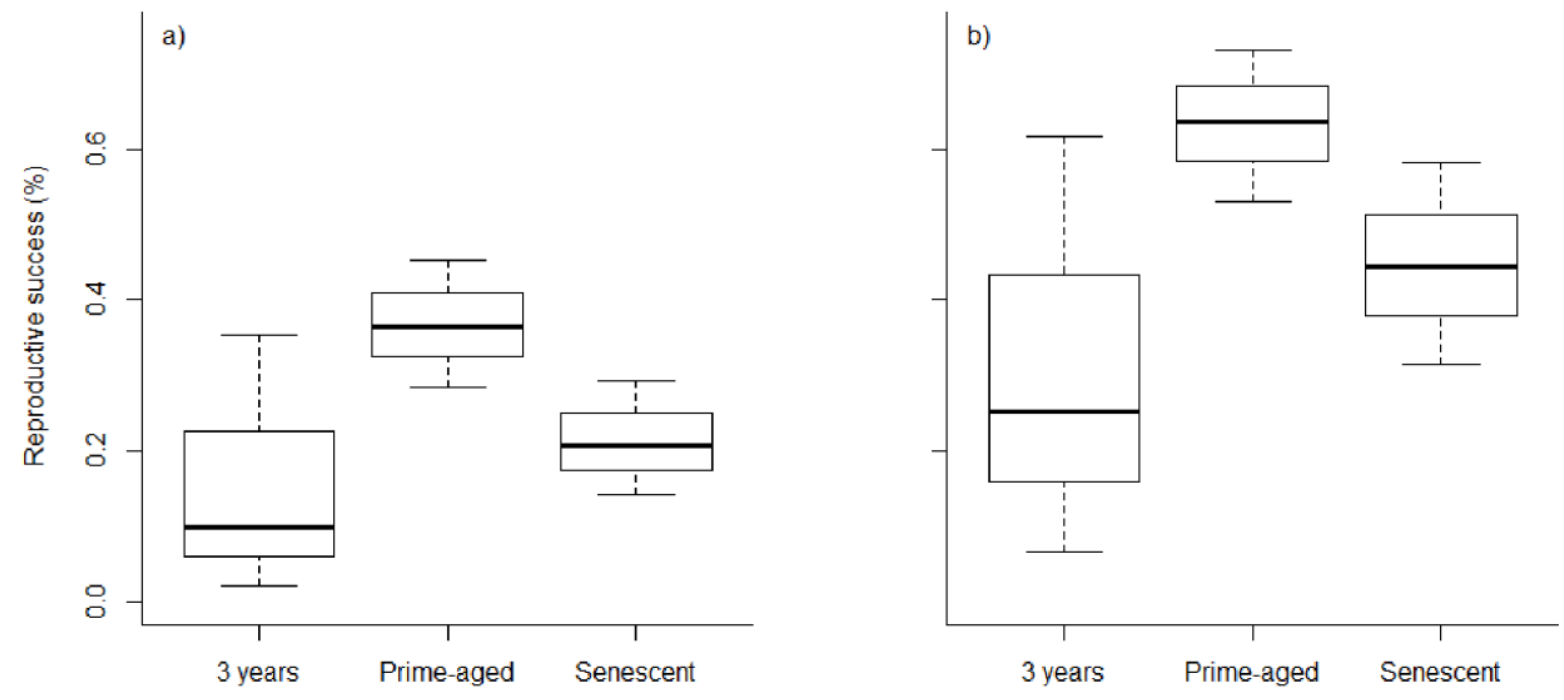
Fig. 3 Effect of reproductive success (production of a kid that survived until autumn) the previous year on current reproductive success of 44 prime-aged (4 - 9 years; 122 female-years) and 31 senescent females ibex (10 years and older; 96 female-years) monitored in Alpi Marittime Natural Park from 1986 to 2006 and in the Alpi Cozie from 1999 to 2006, based on the selected model in table 2.
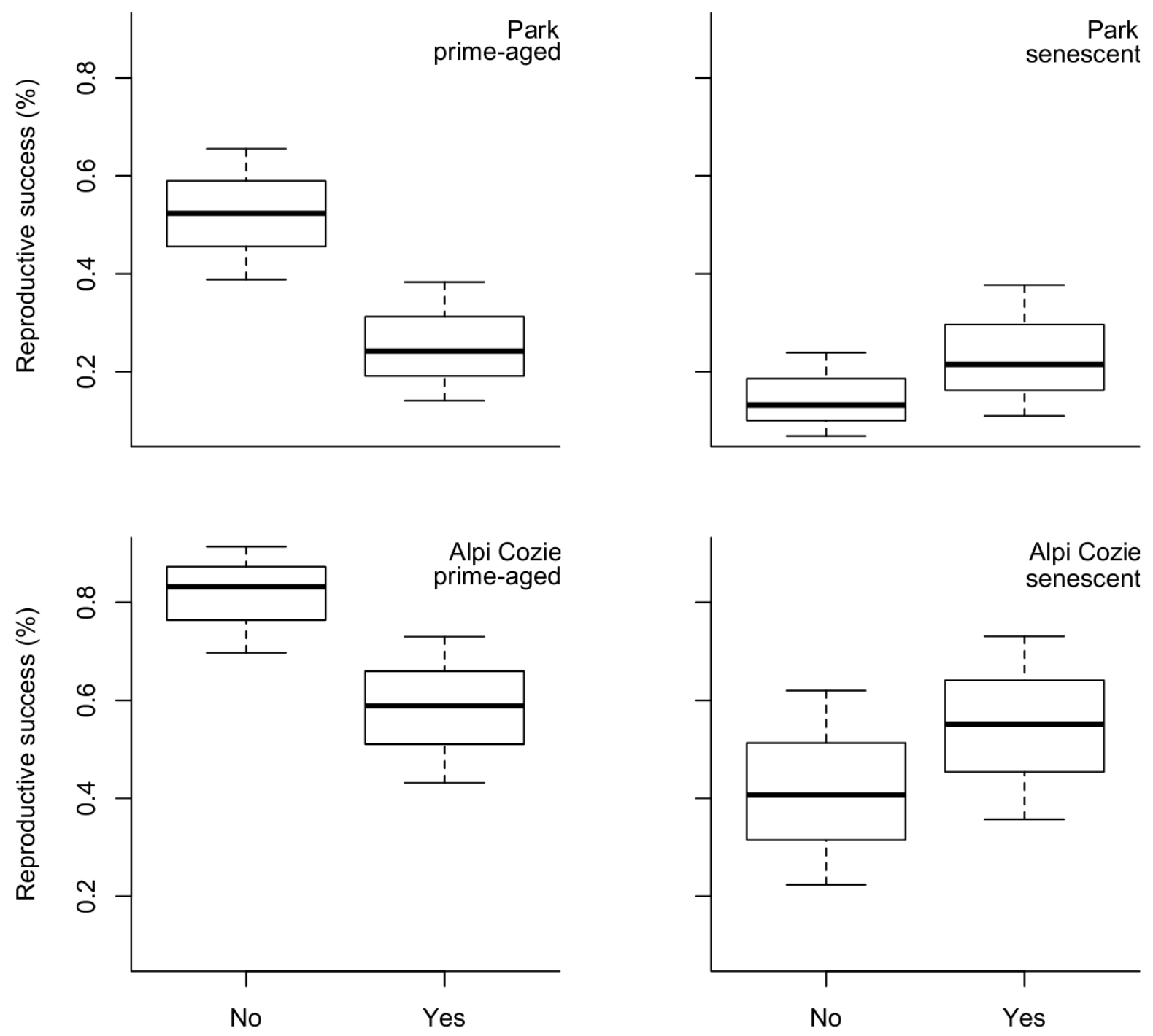
Table 1. Model selection of the effects of age class ( 3 year-old; prime-aged ( $4-9$ years) and senescent (10 years and older)) and study area on production of a kid that survived until autumn of 69 female ibex (326 female-years) monitored in the Alpi Marittime Natural Park from 1986 to 2006 and in the Alpi Cozie from 1999 to 2006 . Female identity as random effect was not statistically significant (LRT: $\chi^{2}=-7.88^{*} 10^{-8} ; \mathrm{P} \sim 1$ ). Selected model in bold.

\begin{tabular}{lll}
\hline Model & d.f. & AICc \\
\hline Age + study area & $\mathbf{5}$ & $\mathbf{3 7 7 . 6 0 6 2}$ \\
Age $*$ study area & 7 & 379.3340 \\
Age & 4 & 393.2292 \\
Null & 2 & 403.7067 \\
\hline
\end{tabular}


Table 2. Model selection of the effects of age class (prime-aged (4 - 9 years) and senescent (10 years and older)), reproductive success (proportion of females producing a kid that survived until autumn) the previous year (pr) and study area on current reproductive success of 59 female ibex (218 female-years) monitored in Alpi Marittime Natural Park from 1986 to 2006 and in the Alpi Cozie from 1999 to 2006 . Female identity as random effect was not statistically significant (LRT: $\chi^{2}$ $\left.=-4.99 * 10^{-8} ; \mathrm{P} \sim 1\right)$. Selected model in bold.

\begin{tabular}{llc}
\hline Model & d.f. & AICc \\
\hline Age + pr + study area + age:pr & $\mathbf{6}$ & $\mathbf{2 5 6 . 0 2 1 0}$ \\
Age + pr + study area + age:pr + age:study area & 7 & 258.0466 \\
Age + pr + study area + age:pr + pr:study area & 7 & 258.1325 \\
Age * pr * study area & 9 & 258.3793 \\
Age + pr + study area + age:pr + age:study area + pr:study area & 8 & 260.1746 \\
Age + pr + study area & 5 & 261.9549 \\
Age + pr + study area + age:study area & 6 & 262.4849 \\
Age + pr + study area + pr:study area & 6 & 264.0163 \\
Age + pr + study area + age:study area + pr:study area & 7 & 264.5205 \\
Null & 2 & 389.7116 \\
\hline
\end{tabular}


Table 3. Observed and permutated estimates of the effect of previous reproduction on current reproduction for prime-aged (4 - 9 years) and senescent female ibex (10 years and older) monitored in Alpi Marittime Natural Park from 1986 to 2006 and in the Alpi Cozie from 1999 to 2006. See text for details on permutation test
Observed
Distribution of simulated estimates
estimates

1st Quartile median mean 3rd Quartile $\mathrm{P}$

\begin{tabular}{lllllll} 
Prime-aged & -1.424 & -0.846 & 0.583 & -0.599 & -0.333 & 0.022 \\
Senescent & 0.548 & -0.372 & 0.004 & -0.062 & 0.3052 & 0.11 \\
\hline
\end{tabular}

